\title{
Recent Experimental Studies on the Blood-Aqueous Barrier: the Anatomical Basis of the Response to Injury
}

\author{
J M BUTLER, W G UNGER and I GRIERSON*
}

London

\begin{abstract}
Summary
In the mammalian eye the tissue layers which effectively separate the neural retina and the transparent refractive media from the circulating blood are generally known as the bloodretinal barrier (BRB) and blood aqueous barrier (BAB) respectively. These have been delineated by morphologically identifying the ultrastructural features which impede the passage of molecules from the blood to the working parts of the eye; physiologically, there is a certain amount of overlap in their function, as there is free diffusion of solutes between the aqueous humour, the vitreous humour and the interstitial tissue of the neural retina. Notwithstanding, it is convenient and appropriate to maintain the distinction as the more recent work has focused on the fine structural aspects of these barrier systems.

The abundant literature which describes the work leading to the identification and characterisation of these barriers has been reviewed in depth with great authority by several eminent researchers, notably the late Giuseppina Raviola, ${ }^{1}$ and Jose Cunha-Vaz. ${ }^{2}$ Certain pathological conditions, trauma - including surgical manipulation, and chemical irritation of the eye can cause significant disruption of these barriers with important clinical consequences. In our laboratory interest has centred around vascular and epithelial changes which occur when the eye is injured and which can lead to a breakdown of the BAB. More recently attention has been drawn to functional and behavioural differences between species, particularly with regard to the relative stability of the barrier.
\end{abstract}

General Organisation of the Blood-aqueous Barrier

In the anterior uvea the blood aqueous barrier is formed by two discrete layers of cells - the endothelium of the iris blood vessels and the inner (non-pigmented) layer of the ciliary epithelium. These exclude from the aqueous and vitreous humours substances such as blood plasma proteins which would compromise transparency and upset the osmotic and chemical equilibrium of the intraocular fluids. However the barrier is not complete; the ciliary vascular endothelium is permeable to blood-borne solutes and such of these that permeate the ciliary stroma can in theory reach the aqueous humour through the stromal crypts in the anterior surface of the iris. This defect in the continuity of the barrier may account for the small amount of plasma proteins identified in the aqueous humour of the anterior chamber of the normal eye $^{3}$ where soluble protein levels are around $1 \%$ of those found in blood plasma.

\section{The Anterior Uveal Vasculature}

The blood vessels of the ciliary processes comprise an extensively ramified bed of fenestrated venule-like capillaries with a discontinuous folded endothelium suggestive of high permeability. $1,4,5$ These loosely interwoven vessels lie close to the epithelium and would appear to provide an effectively large pool of plasma fluid for the formation of aqueous humour. Plasmoid 
material can pass rapidly by paracellular diffusion from the vessel lumen into the stroma and smaller crystalloid and organic molecules may cross the endothelium through the fenestrations. ${ }^{6}$ An intravenously administered protein tracer may therefore rapidly penetrate into the ciliary stroma but is prevented from entering the posterior aqueous chamber by the tight intercellular junctions - zonulae occludentes - at the apico-lateral fusion points of the nonpigmented epithelial cells. . $^{1,-11}$

In contrast, the iris blood vessels form spiralling radial loops of unfenestrated homogeneous capillaries from which effusion of plasma constituents is restricted by tight junctions which effectively close the lateral endothelial clefts. ${ }^{4,8,9,12,13}$ In the rabbit, primate and mouse these vessels can be regarded as quite impermeable and thus, since there is no epithelium on the anterior surface of the iris, form part of the BAB. ${ }^{1,10,11.14,15}$ In the rat and perhaps cat and pig iris the vessels are, by comparison, somewhat more permeable and may readily become 'labelled' with intravenously injected colloidal carbon (see below; ${ }^{16.18}$ ).

\section{The Ciliary Complex}

In the rabbit the ciliary complex includes about 45 short ciliary processes alternating radially with the same number of long iridial processes, both of which are interlinked by a ring of tissue - the ciliary ridge - which extends from the ciliary body. ${ }^{19,20}$ The iridial processes project through the ciliary ridge and run radially along the posterior side of the iris to which they are joined by short stromal projections. The short processes terminate on the top of the ciliary ridge. These structures are so arranged as to form pockets between the iridial processes and the iris which are open to the posterior chamber. The inner, non-pigmented epithelium which lines these pockets consists of flat, squamous cells ${ }^{19}$ which undergo disruptive changes during injury. In contrast, the epithelial cells covering the short processes and the posterior parts of the iridial processes are of a relatively stable columnar-type and more resistant to such changes (see Fig 1). The ciliary epithelium is also the site of active aqueous humour secretion $^{21}$ and displays a selective capability for the removal of specific substances such as prostaglandin from the eye, ${ }^{22}$ so that disturbance of barrier function may therefore also effect metabolite levels by compromising this uptake. ${ }^{23}$ Butler and Raviola ${ }^{24.25}$ have also demonstrated a transendothelial microvisicular transport process in iris as well as retinal vessels which moves endocytosed material unidirectionally from the abluminal ocular compartment to the blood.

\section{The Vascular Response to Injury}

When the anterior segment of the mammalian eye is subjected to painful or irritant stimulation it may react with pupillary constriction, uveal vasodilation, a rise in intraocular pressure and leakage of plasma proteins into the aqueous humour. This protein leakage is generally associated with a breakdown of the BAB adjacent to

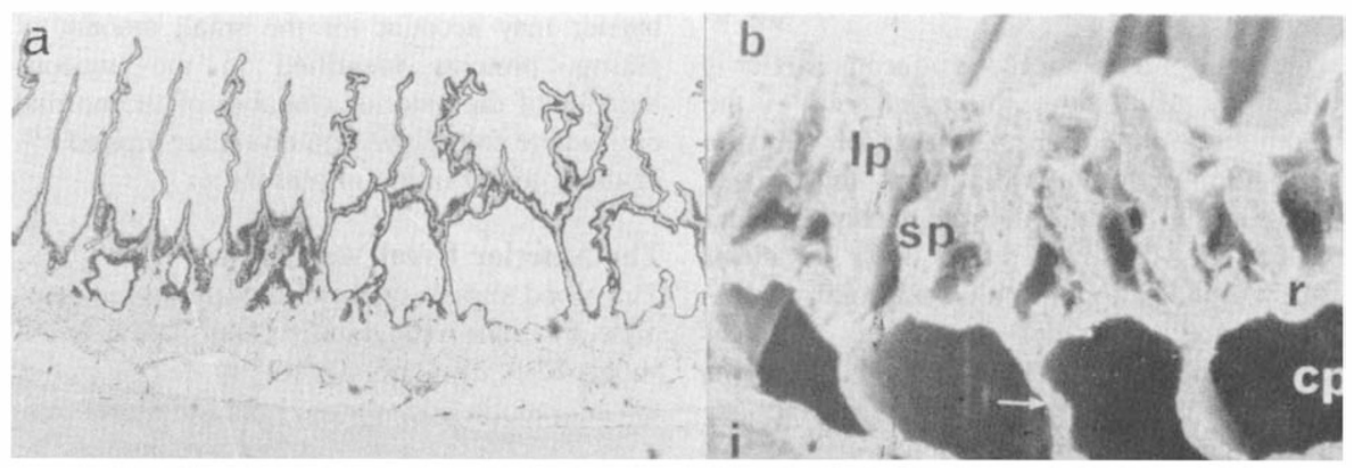

Fig. 1. Iris-ciliary complex of the rabbit eye. (a) coronal section showing the short ciliary processes and the larger irideal processes interlinked by a ciliary ridge. Whereas the ciliary processes run on top of the ridge, the irideal processes extend through the ridge and make stromal connections with the iris. (b) scanning electron microscopic view of the rabbit iris-ciliary tissue cut transversely to demonstrate the structural relationship of the irideal and the ciliary processes which together with the posterior surface of the iris form pockets communicating with the posterior chamber. 
the posterior chamber; sodium fluorescein injected intravascularly appears rapidly in the anterior chamber entering through the pupil and associated with dense plasmoid exudate. Chemical irritation, mechanical (surgical) trauma, laser irradiation of the iris or paracentesis of aqueous humour from the anterior chamber each produce a similar response.

The rapid rise in IOP which occurs in certain species, notably the rabbit, following various forms of noxious stimuli is the result of several factors. Much of the immediate response may be due to blepharospasm and reflex contraction of the extraocular muscles. Simultaneously there is a sudden rise in the blood volume of the anterior uvea with a subsequent increase in ultrafiltration and plasma extravasation. Owing to the limited expansion of the scleral envelope the ocular hypertension persists until either the aqueous outflow increases to compensate for this or the tide of incoming fluid is arrested by congestive and oedematous changes in the ciliary and iridial processes. After severe leakage into the stroma the vessels may collapse or display haemostasis leading to a decrease in aqueous formation and hypotony - commonly found after acute inflammatory episodes.

In the normal eye only a certain proportion of the iris and ciliary vascular beds appears to be open and perfused with blood. In response to noxious stimulation of the anterior segment these capillary beds become extensively dilated and insanguinated and many more vessels become visible. An increase in the ocular pulse has been observed within 10 minutes of injecting PGE1, ${ }^{26}$ reflecting both dilation of the capillaries and a relaxation of the afferent vessels. However, from studies with thermal probes Starr ${ }^{27}$ came to the conclusion that there is little overall increase in anterior uveal blood flow after administering prostaglandin, but that increased flow does occur in ciliary tissue, possibly representing a regional shunt. By using intravenously injected colloidal carbon as a marker of excessive vascular permeability (c.f. ${ }^{28}$ ) Cole $^{29}$ found that it is only in the ciliary region that gross permeability changes and significant plasma extravasation occur in the rabbit. Provided that time (15-30 minutes) is allowed for the reticular endothelium to remove the carbon from the general circulation it is only the vessel walls of the ciliary and iridial processes, and not those of the iris, which become 'labelled' after noxious stimulation. Where there is excessive leakage the carbon particles perveate the expanded intercellular clefts of the ciliary venule endothelium and become entrapped in the basement membrane (see Fig. 2;29-32). Koseki ${ }^{33}$ described the arrangement of collagen fibres in the adventitia surrounding the vessels of the rabbit ciliary body and noted that those in the iridial processes were thinner and less dense than those around the capillaries of the short ciliary processes, so providing less resistance to distension. This difference may be at least partly responsible for the differential fragility of the barrier in these regions for, as a result of reflex vasodilation and

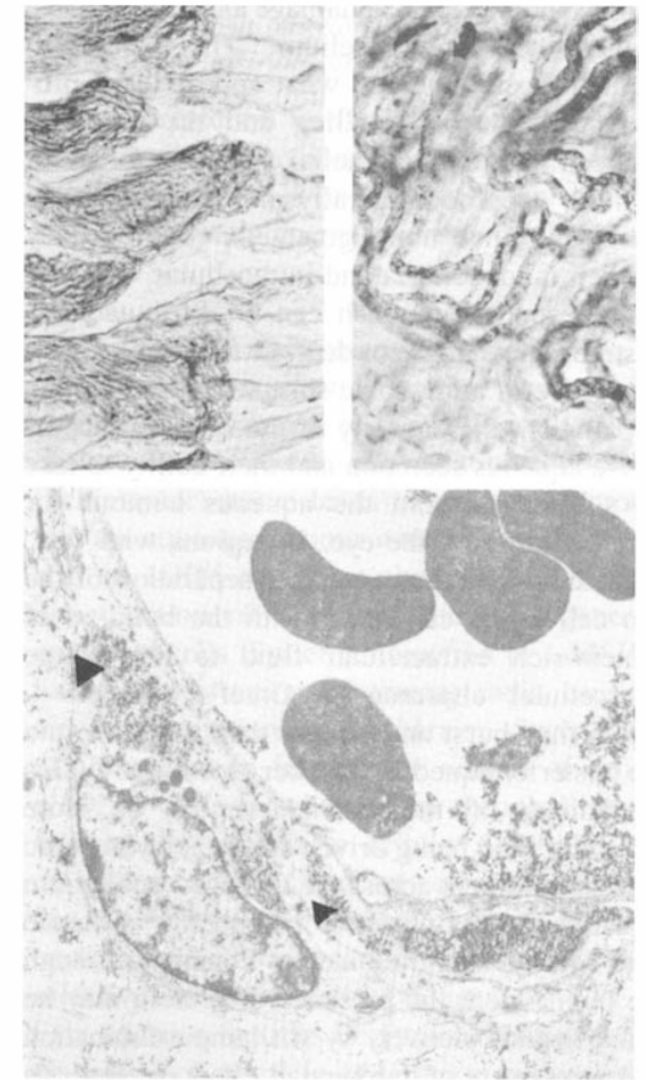

Fig. 2 Colloidal carbon labelling of the ciliary capillaries after anterior chamber paracentesis. The top two panels show the staining of the vessels by intravenously injected carbon as seen in excised whole mount preparations. By transmission electron microscopy (bottom panel), the carbon particles are seen to pervade dilated intercellular clefts and to become trapped by the endothelial basement membrane. 
increased perfusion pressure in the ciliary vessels, those whose walls are weakest are more prone to suffer diminished endothelial integrity.

What happens after the vessels dilate is largely a matter for speculation. One view supposes that the breakdown of the $\mathrm{BAB}$ is due to shrinkage of the pigmented epithelial cells, perhaps under some neurogenic influence $\left({ }^{34}\right.$; see below), with degeneration of the junctional complexes and separation of the two cell layers. It is just as likely, however, to occur as a direct result of the gross vasodilation and oedema in the underlying tissues in which the intercellular clefts and their interdigitations open, allowing plasmoid fluid to leak into the interstitial spaces of the processes, causing hydrostatic and osmotic swelling of the stroma and mechanical damage and degenerative changes to the epithelium. The pigmented epithelial cells undergo what appear to be pronounced hydropic swelling and the junctions between the two epithelial layers pull apart, forming gaps both apically and at their lateral margins. The non-pigmented cells display swollen mitochondria and intracellular vesiculation, beyond that which can be attributable to postmortem changes or delayed-fixation artefact, suggestive of an hypoxic state which is likely to impair both the capacity of the cells to support active aqueous secretion and their ability to take up substances from the aqueous humour for elimination from the eye. In regions with thin, squamous epithelia, complete separation of the two cell layers can occur with the build-up of protein-rich extracellular fluid to form large intercellular cisternae - Greef's vesicles which may burst and release their contents into the posterior aqueous chamber (see Fig. 3). This breakdown of the barrier results in more plasmoid fluid being driven down the hydrostatic pressure gradient across the damaged epithelium directly into the posterior chamber ${ }^{29,32}$ whence it is carried into the anterior chamber through the pupil. Here the presence of protein may be quantified subjectively by slit-lamp examination and assessment of the Tyndall effect or 'aqueous flare'. In the rabbit disruption of the BAB can also be dramatically illustrated by leakage of intravenously injected fluorescein ${ }^{29,35}$ which, associated with a dense plasmoid exudate, enters the anterior chamber through the pupil and gravitates into the lower quadrants, eventually filling the anterior chamber (see

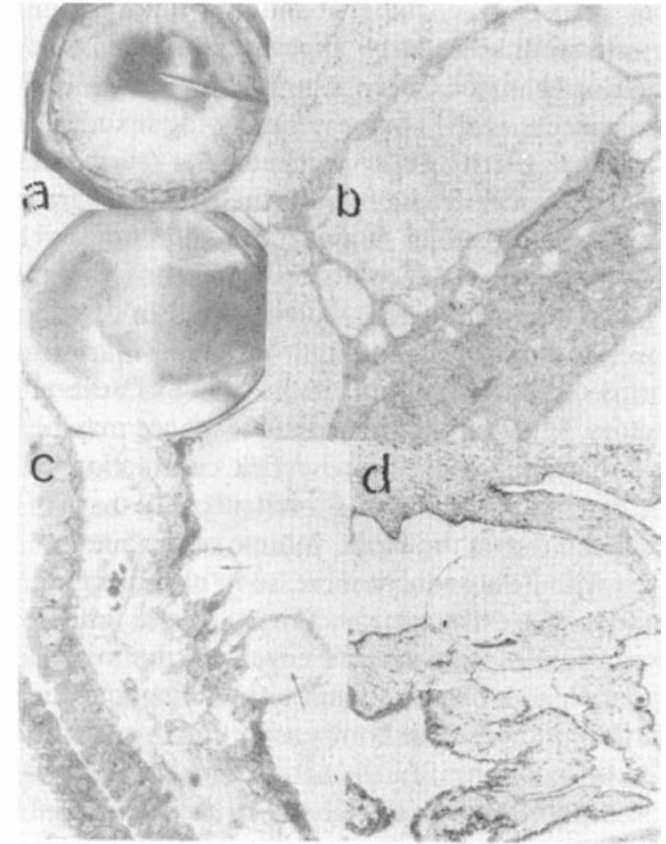

Fig. 3. Pronounced breakdown of the rabbit bloodaqueous barrier due to disruptive alterations of the ciliary epithelium overlaying the irideal processes and ciliary ridge. (a) Intravenously injected fluorescein rapidly enters the anterior chamber through the pupil together with dense plasmoid material in eyes which have been subjected to aqueous paracentesis or laser irradiation of the iris. (b) The pigmented ciliary epithelium on the irideal processes appears to undergo hydropic swelling and dilatation of the intercellular spaces. (c) and (d) As a result of oedema and degenerative changes, the two epithelial layers separate along the anterior surface of the ciliary ridge and the irideal processes form large vacuoles which burst to release their contents into the posterior chamber.

Fig. $3 a ;{ }^{29-32,36,37}$ ). Some of the dye may also reach the anterior chamber by diffusion from the iridial processes through stromal connections into the iris. ${ }^{20,38,39}$

\section{Species Differences in the Strength of the Blood-aqueous Barrier}

There are significant species differences in the responsiveness of the eye to injury, ${ }^{49}$ the rabbit being particularly reactive and primates generally much less so. Animals with different lifestyles and physiognomy clearly display various degrees of sensitivity; in terms of suitability as an animal model for reproducing the 

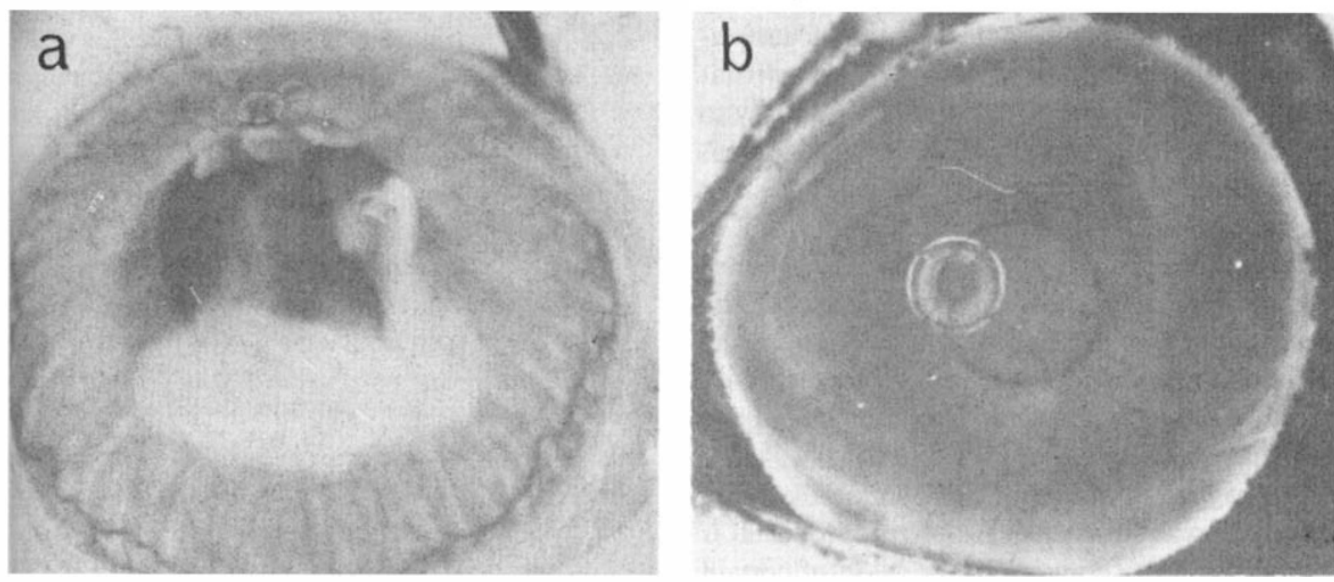

Fig. 4. The blood-aqueous barrier of the primate eye is far less sensitive to irritation than that of the rabbit eye. Fluorescein injected intravenously after paracentesis enters the rabbit anterior chamber (a) very rapidly when compared with that of the monkey (b). Notable fluorescence of the irido-corneal angle is seen.

human ocular injury response the rabbit is far from ideal. In the latter species the disruption of the barrier after injury is sudden and intense and after anterior chamber paracentesis the soluble protein levels can increase from normal aqueous levels of about $0.4 \mathrm{mg} / \mathrm{ml}$ to as much as $40 \mathrm{mg} / \mathrm{ml}$ in the secondary aqueous humour. ${ }^{32}$ By comparison, in the owl monkey the aqueous protein level only rises from $0.3 \mathrm{mg} / \mathrm{ml}$ to $0.7 \mathrm{mg} / \mathrm{ml}$ and the escape of intravenously injected sodium fluorescein into the aqueous chambers is correspondingly less (see Fig. $\left.4 ; ;^{11,32}\right)$. Similarly, the hypertensive response of the human eye and the associated disruption of the BAB after ruby laser irradiation of the iris is very slight in comparison to that occurring in the rabbit $^{41}$ and PGE2 infused into the anterior chamber of the cat or monkey eye has much less effect than in the rabbit. ${ }^{42,43}$ These differences may be largely attributable to the anatomical peculiarities of the rabbit, since the higher mammals with stereoscopic vision lack both the extensive and delicate iridial processes and the squamous epithelium which covers these and the ciliary ridge. ${ }^{30,40}$ The latter features have possibly evolved in the rabbit and other thicketfrequenting creatures to allow the immediate access of plasma constituents into the anterior chamber following episodes of trauma such as perforation of the cornea. Such a facility would seem to have been lost through evolutionary divergence in the higher mammals where the facial topography and deeper orbit provides greater protection to the eye. Notwithstanding, there are still many similarities in the nature of the response and it is thought likely that the underlying cellular mechanisms are common to all.

\section{Neurohumoral Influences on the BAB}

There is substantial evidence that nerve activity can induce disruption of the BAB in the region of the ciliary processes. Stimulation of the IIIrd (oculomotor) nerve leads to leakage of protein into the aqueous humour without any significant rise in $\mathrm{IOP}^{44}$ which is thought to involve a direct action of this nerve on the pigmented epithelial cells. Systemic injection of a-MSH or local administration of prostaglandin causes a similar disruption of the barrier. Such effects would appear to involve the release of prostaglandins and are enhanced by theophylline and inhibited by imidazole (cyclic AMP-phosphodiesterase inhibitor and activator respectively), and also inhibited by beta-adrenergic blockade or by previous treatment with capsaicin - a selective sensory neurolytic agent. ${ }^{44-47}$ In the light of these findings Bengtsson ${ }^{48}$ has proposed that elevation of cyclic AMP is a common link in effecting the epithelial changes and breakdown of the barrier. The possibility that PGs might have a direct disruptive effect on the epithelium is not supported in studies in which fresh isolated iris-ciliary body preprations were exposed to PGE1 or PGE2. ${ }^{49-51}$ In these no obvious ultrastructural changes and little if any 
increase in flow conductivity across the ciliary epithelium were found, indicating that degenerative changes which occur in vivo during irritation or after PG administration are secondary to the vascular changes and the ensuing oedema. Transepithelial potential difference and short circuit current - indicative of a net flux of actively transported ions - across in vitro preparations are virtually unaffected by the presence of prostaglandins, ${ }^{49}$ discounting the likelihood that an increase in secretory activity might contribute to ocular hypertension in the early stages of the injury response.

The triggering stimulus from which the pupil constriction and the vasodilation are produced is believed to involve antidromic release of certain peptide mediators from primary afferent nerves of trigeminal origin; ${ }^{52-54}$ in the rabbit trigeminal denervation largely prevents manifestation of anterior uveal responses to noxious stimulation, including those which are known to involve PG synthesis and release, e.g. laser irradiation of the iris. ${ }^{52}$ Therefore, although prostaglandins do not appear to have a direct effect upon the ciliary epithelium, they do interact with sensory nerves to promote vasodilator activity in the rabbit eye $^{52}$ and thus may well influence epithelial integrity indirectly through antidromic sensory mechanisms. Even the gross vasodilation and stromal oedema which occurs in the ciliary and iridial processes after paracentesis from the anterior chamber is attenuated after sensory denervation (see Fig. 5), indicating that this effect is not simply due to the pressure gradient created by the fall in IOP but involves the release of an active vasodilator substance. Whether or not this substance also directly promotes epithelial separation is not known. Thus the integrity of the barrier, in the rabbit at least, would therefore appear to be largely dependent upon limitation of the degree of plasma extravasation and osmotic pressure in the processes. The neuromediator which initiates the pressure rise and the increase in vascular permeability is now believed to be calcitonin gene-related peptide $\left(\right.$ CGRP $\left.^{53}\right)$.

\section{Conclusions}

The blood-ocular barriers are functional entities which depend upon the integrity of the intraocular vessels and the epithelia which separate the blood plasma space from the intra-
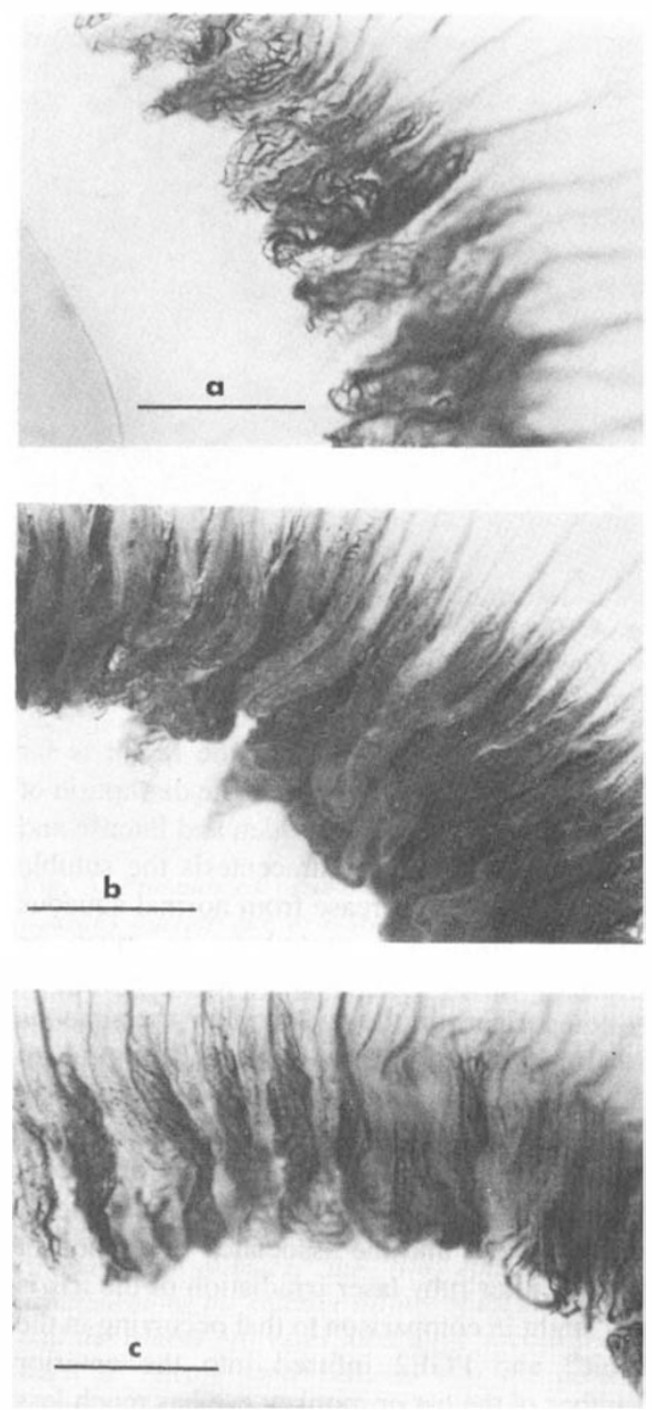

Fig 5. (a) Posterior aspect of the ciliary and iridial processes of a normal albino rabbit eye 20 minutes after intravenous injection of $5 \mathrm{ml}$ colloidal carbon (Pelikan ink; batch no. C11/143la; diluted 1:1 with normal saline). Carbon is retained in the vascular system but there is no leakage into the stroma. (b) The same aspect of a normal and (c) sensorily denervated rabbit eye after simultaneous withdrawal of $100 \mathrm{ul}$ of aqueous humour. Colloidal carbon (as above) has been injected intravenously 10 minutes after the paracentesis and 20 minutes allowed for this to clear from the general circulation. In the normal eye the processes appear oedematous and carbon extravasation is pronounced. In the denervated eye this is much less evident and carbon labelling is largely restricted to the vessel walls. $1 \mu \mathrm{m}$ bars are superimposed. 
ocular fluid compartments. Disruption of the blood-aqueous barrier can occur as the consequence of the action of endogenous vasodilator substances released from sensory afferents by antidromic $r$ stimulation and the direct action of prostaglandins which also facilitate immediate neurogenic vasodilation. Ciliary vasodilation and increased permeability in lower mammals lead to a precipitous breakdown in the BAB with substantial amounts of plasma protein pervading the aqueous chambers.

\section{References}

' Raviola G. The structural basis of the bloodaqueous barriers. Exp Eye Res 1977, 25 (Suppl.): 27-63.

${ }^{2}$ Cunha-Vaz JG. The blood-retinal barriers. Plenum Press 1980, New York.

${ }^{3}$ Davson H. The Eye, Vol. I. Vegetative physiology and biochemistry. Academic Press 1982, London.

${ }^{4}$ Hogan MJ, Alvarado JA, Weddell JE. Histology of the human eye. WG Saunders 1971, Philadelphia.

${ }^{5}$ Bill A. Blood circulation and fluid dynamics in the eye. Physiol Rev 1975, 55: 383-417.

${ }^{6}$ Bill A. Capillary permeability to and extravascular dynamics of myoglobin, albumin and gammaglobulin in the uvea. Acta Physiol Scand 1968, 73: 204-19.

${ }^{7}$ Shiose Y. Electron microscopic studies on bloodretinal and blood-aqueous barriers. Jap $J$ Ophthalmol 1970, 14: 73-87.

${ }^{8}$ Smith RS. Ultrastructural studies of the bloodaqueous barrier. I. Transport of an electron dense tracer in the iris and ciliary body of the mouse. Am J Ophthalmol 1971, 71: 1066-77.

${ }^{9}$ Vegge T. An electron microscopic study of the permeability of iris capillaries to horseradish peroxidase in the vervet monkey (Cercopithecus aethiops). $Z f$ Zellforsch 1971, 121: 74-81.

${ }^{10}$ Shabo AL and Maxwell DS. The blood-aqueous barrier to tracer protein: a light and electron microscopic study of the primate ciliary process. Microvasc Res 1972, 4: 142-58.

"Raviola G. Effects of paracentesis on the bloodaqueous barrier: an electron microscopic study on Macaca mulatta using horseradish peroxidase as a tracer. Invest Ophthalmol 1974, 13: 828-58.

${ }^{12}$ Vegge $\mathrm{T}$ and Ringvold $\mathrm{A}$. Ultrastructure of the cell wall of human iris vessels. $Z f$ Zellforsch 1969, 94: $119-31$

${ }_{13}$ Vegge T, Neufeld AH and Sears ML. Morphology of the breakdown of the blood-aqueous barrier in the ciliary processes of the rabbit eye after prostaglandin $\mathrm{E}_{2}$. Invest Ophthalmol 1975, 14: 33-6.
${ }^{14}$ Cunha-Vaz JG. PhD Thesis 1966, University of London.

${ }^{15}$ Smith RS and Rudt LA. Ultrastructural studies of the blood-aqueous barrier. 2 The barrier to horseradish peroxidase in primates. $\mathrm{Am} J$ Ophthalmol 76: 937-47.

${ }^{16}$ Saari M. Fine structure of the microcirculatory bed of the pig iris. Ann Med Exp Biol Fenn 1972, 50: 12-23.

${ }^{17}$ Shakib $M$ and Cunha-Vaz JG. Studies on the permeability of the blood-retinal barrier. Exp Eye Res 1966, 5: 229-34.

${ }^{18}$ Szalay J, Nunziata B, Hendkind P. Permeability of the irideal blood vessels. Exp Eye Res 1975, 21: 531-43.

${ }^{19}$ Kozart DM. Light and electron microscope study of regional morphologic differences in the processes of the ciliary body in the rabbit. Invest Ophthalmol 1968, 7: 15-33.

${ }^{20}$ Weingeist TA. The structure of the developing and adult ciliary complex of the rabbit eye: A gross light and electron microscopic study. Doc Ophthalmol 1972, 28: 206-57.

${ }^{21}$ Cole DF. Aqueous humour formation. Doc Ophthalmol 1966, 21: 116-238.

${ }^{22}$ Bito L and Salvador E. Intraocular fluid dynamics. III. The site and mechanism of prostaglandin transfer across the blood intraocular fluid barriers. Exp Eye Res 1972, 14: 233-41.

${ }^{23}$ Bito LZ. The effects of experimental uveitis on anterior uveal prostaglandin transport and aqueous humor composition. Invest Ophthalmol 1974, 13: 959-66.

${ }^{24}$ Raviola G and Butler JM. Rabbit retinal blood vessels are impermeable to horseradish peroxidase (HRP) injected intravenously, but are penetrated by HRP injected into the vitreous body. Proc Int Soc Eye Res 1982, II: 78.

${ }^{25}$ Raviola G and Butler JM. Morphological evidence for the transfer of anionic macromolecules from the interior of the eye to the blood stream. Curr Eye Res 1985, 4: 503-16.

${ }^{26}$ Beitch BR and Eakins KE. The effects of prostaglandins on the intraocular pressure of the rabbit. Br J Pharmacol 1969, 37: 158-67.

${ }^{27}$ Starr MS. Effects of prostaglandin on blood flow in the rabbit eye. Exp Eye Res 1971, 11: 161-9.

${ }^{28}$ Majno G, Palade GE and Schoefl GI. Studies on inflammation II. The site of action of histamine and serotonin along the vascular tree; a topographical study. J Biophys Biochem. Cytol 1961, 11: $607-20$.

${ }^{29}$ Cole DF. The site of breakdown of the bloodaqueous barrier under the influence of vasodilator drugs. Exp Eye Res 1974, 19: 591-607. 
${ }^{30}$ Unger WG. Changes in the anterior uveal vessels and epithelium in the inflammed rabbit eye. Biblthca anat 1979, 18: 278-83.

${ }^{31}$ Unger WG, Perkins ES, Bass MS. The response of the rabbit eye to laser irradiation of the iris. Exp Eye Res 1974, 19: 367-77.

${ }^{32}$ Unger WG, Hammond BR and Cole DF. Disruption of the blood-aqueous barrier following paracentesis in the rabbit. Exp Eye Res 1975, 20: 255-70.

${ }^{33}$ Koseki T. Scanning electron microscopic study of the adventitial aspects of the microvessels in the rabbit ciliary body. Arch Soc Ophthalmol Jap 1983, 87: 1157-65.

${ }^{34}$ Uusitalo R, Palkama A, Stjernschantz J. An electron microscopical study of the bloodaqueous barrier in the ciliary body and iris of the rabbit. Exp Eye Res 1973, 17: 49-63.

${ }^{35}$ Edwards JE. A new apparatus for fluorescein angiography of the anterior segment of the eye. J Physiol (Lond) 1974, 246: 39-40P.

${ }^{36}$ Unger WG, Cole DF, Bass MS. Prostaglandin and neurogenically mediated ocular response to laser irradiation of the rabbit iris. Exp Eye Res 1977, 25: 209-20.

${ }^{37}$ Bhattacherjee PG and Hammond BR. Inhibition of increased permeability of the blood-aqueous barrier by non-steroidal anti-inflammatory compounds. Exp Eye Res 1975, 21: 499-505.

${ }^{38}$ Whitelocke RAF and Eakins KE. Vascular changes in the anterior uvea of the rabbit produced by prostaglandins. Arch Ophthalmol 1973, 89: 495-9.

${ }^{39}$ Laties AM, Neufeld AH, Vegge T, Sears ML. Differential reactivity of rabbit iris and ciliary processes to topically applied prostaglandin $\mathrm{E}_{2}$ (dinoprostone). Arch Ophthalmol 1976, 94: 1966-71.

${ }^{40}$ Bito LZ. Comparison of the ocular hypotensive efficacy of eicosanoids and related compounds. Exp Eye Res 1984, 38: 181-94.

${ }^{41}$ Unger WG, Brown NAP and Edwards J. The response of the human eye to laser irradiation of the iris. Br J Ophthalmol 1977, 61: 148-53.

${ }^{42}$ Eakins KE. Increased intraocular pressure produced by prostaglandin $\mathrm{E}_{1}$ and $\mathrm{E}_{2}$ in the cat eye. Exp Eye Res 1970, 10: 87-92.
${ }^{43}$ Kelly RGM and Starr M. Effects of prostaglandins and prostaglandin antagonists on intraocular pressure and protein in the monkey eye. Canad $J$ Ophthalmol 1971, 8: 205-11.

${ }^{44}$ Uusitalo R, Stjernschantz J, Palkama A. Studies on parasympathetic control of the blood-aqueous barrier in the ciliary body and iris in the rabbit. Exp Eye Res 1974, 19: 125-34.

${ }^{45}$ Bengtsson E. The effect of imidazole on the disruption of the blood-aqueous barrier in the rabbit eye. Invest Ophthalmol 1976, 15: 315-20.

${ }^{46}$ Bynke G, Hakanson R, Hong J. Ocular responses evoked by capsaicin and prostaglandin $E_{2}$ are inhibited by substance $\mathrm{P}$ antagonist. Experentia 1973, 39: 986-98.

${ }^{47}$ Holmdahl G and Bengtsson E. The effect of timolol maleate on the disruption of the bloodaqueous barrier in the rabbit eye. Invest Ophthalmol 1981, 20: 726-32.

${ }^{48}$ Bengtsson E. The effect of theophylline on the blood-aqueous barrier in the rabbit eye. Invest Ophthalmol 1977, 16: 636-40.

${ }^{49}$ Green K. Permeability properties of the ciliary epithelium in response to prostaglandins. Invest Ophthalmol 1973, 12: 752-8.

${ }^{50}$ Pedersen O. Electron microscopic studies on the blood aqueous barrier of prostaglandin-treated rabbit eyes. I. Iridial and ciliary processes. Acta Ophthalmol 1975, 53: 685-98.

${ }^{51}$ Pederson $\mathrm{OO}$ and Tonjum AM. In vitro studies on peroxidase movement in the epithelium of prostaglandin-treated rabbit ciliary bodies. Acta Ophthalmol 1975, 53: 673-84.

52 Butler JM and Hammond BR. The effects of sensory denervation on the responses of the rabbit eye to prostaglandin $\mathrm{E}_{2}$, bradykinin and substance P. Br J Pharmacol 1980, 69: 495-502.

${ }^{53}$ Butler JM, Unger WG, Cole DF. Axon reflex in ocular injury: sensory mediation of the response to laser irradiation of the iris. Quart $J$ Exp Physiol 1980, 64: 261-72.

${ }^{54}$ Unger WG, Terenghi G, Ghatei MA, Butler JM, Polak JM, Bloom SR. Calcitonin gene-related polypeptide as a mediator of the neurogenic ocular injury response. J Ocular Pharmacol 1985, 1: 185-95. 